\title{
The effect of time of day when dairy heifers are introduced to a group containing mature cows on welfare and performance
}

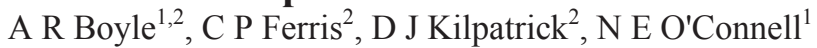 \\ ${ }^{1}$ Queens University, Belfast, United Kingdom, ${ }^{2}$ Agri-Food and Biosciences Institute, Belfast, United Kingdom \\ Email: alastair.boyle@afbini.gov.uk
}

Introduction The integration of dairy heifers into the main herd during the post calving period can have negative effects on the heifer's welfare and productivity (Gonzalez et al, 2003). This appears to be related to the fact that heifers attain low social status when entering the milking herd and therefore are subjected to increased levels of bullying and aggression (Wierenga, 1990; Knierim, 1999). The aim of this study was to assess if the time of day (i.e. after 'AM' or 'PM' milking) when freshly-calved heifers are introduced to a group containing mature cows influences the heifers' welfare and performance.

Materials and methods Twenty-eight Holstein Friesian (HF) heifers were used in this study, with heifers introduced into a group containing mature cows between approximately 24-36 hours post calving. Animals were housed in cubicle pens with solid floors. Two treatments were examined, with heifers introduced either 1) after morning milking (AM: between 06:0008:00 hours) or 2) after evening milking (PM: between 16:00-18:00 hours). Treatments were replicated five times, with treatments balanced for genetic merit, body weight, condition score and sire. In each replicate, a resident group containing $12 \mathrm{HF}$ cows and 6 non-experimental HF heifers was established at least 7 days prior to the introduction of the first experimental heifer. In replicates 1 to 4 , three non-experimental heifers were replaced by heifers in Treatment 1 , and three by heifers in Treatment 2. In replicate 5, two non-experimental animals were replaced by heifers in Treatment 1 and two were replaced by heifers in treatment 2. In both treatments, experimental heifers were introduced approximately 30 minutes after the resident group returned from milking (Day 1). The social and exploratory behaviour of each heifer was recorded directly over a 2-hour period immediately after introduction to the group on Day 1 . These behaviours were observed for each experimental heifer during 4 x 5 minute continuous observations at 30-min intervals during the 2 hour post-feeding period on one day each week for 1 month post introduction. A sub-category of social behaviours; 'social cohesive' was created for analysis and included the behaviours licking another animal/rubbing heads. The heifers' lying and standing behaviour was monitored by automated data loggers (Tinytag Plus, Re-Ed volt, Gemini dataloggers (UK) Ltd., Chichester, UK). These were fitted for 24 hours on Day 1, and for a continuous 24 hour period each week during the first 4 weeks post-introduction. Milk yield of heifers was recorded daily from day 5 to 35 post-calving. Mean behavioural data for the heifers from each treatment within each replicate was analysed by ANOVA. Individual production data was analysed by REML with PTA values used as covariates.

Results On Day 1, animals in the AM treatment received more threats $(\mathrm{P}<0.05)$ and butts $(\mathrm{P}<0.001)$ than those in the $\mathrm{PM}$ treatment (Table 1). There was a tendency for heifers introduced at AM to be chased more than those introduced at PM $(\mathrm{P}=0.05)$. Heifers introduced at $\mathrm{PM}$ were more socially cohesive than those in the AM treatment $(\mathrm{P}<0.05)$. No significant treatment effect was found for total hours lying, with heifers in both treatments lying for an averaged 7.5 hours/day $(\mathrm{P}>0.05)$. During Day 1 heifers in both treatments lay for less than 4 hours/day.

Table 1 Effect of timing of introduction on heifer behaviour during Day 1 and on performance during the first month post calving

\begin{tabular}{|c|c|c|c|c|}
\hline & $\mathrm{AM}$ & PM & SED & Significance \\
\hline \multicolumn{5}{|c|}{ Behaviour (frequency/minute) } \\
\hline Receive threat & 0.01 & 0.00 & 0.002 & $*$ \\
\hline Receive shoulder & 0.02 & 0.01 & 0.008 & NS \\
\hline Receive butt & 0.16 & 0.05 & 0.013 & $* * *$ \\
\hline Receive chase & 0.01 & 0.00 & 0.004 & NS \\
\hline Receive nosing & 0.05 & 0.06 & 0.020 & NS \\
\hline Social cohesive & 0.01 & 0.04 & 0.009 & $*$ \\
\hline \multicolumn{5}{|l|}{ Performance ( $\mathrm{kg} /$ day) } \\
\hline Milk yield & 25.2 & 25.9 & 0.70 & NS \\
\hline Fat plus protein yield & 2.02 & 2.06 & 0.107 & NS \\
\hline
\end{tabular}

Conclusions Introducing heifers to the resident group after PM milking appeared to improve welfare in the immediate post mixing period by reducing levels of aggression to which they were exposed. However, this did not promote increased lying behaviour. There did not appear to be any long term effects of treatment on behaviour or performance.

Acknowledgements The authors gratefully acknowledge funding from AgriSearch and DARDNI.

\section{References}

Gonzalez, M., Yabuta, A.K. and Galindo, F. 2003. Behavioural and adrenal activity of first parturition and multiparous cows under a competitive situation. Applied Animal Behaviour Science 83, 259-266.

Knierim, U. 1999. The behaviour of heifers after single or group introduction to the dairy herd. KBTL SCHRIFT 382, $115-$ 120.

Wierenga, H.K. 1990. Social dominance in dairy cattle and the influences of housing and management. Applied Animal Behaviour Science 27, 201-229. 